NASZA DERMATOLOGIA Onlin OUR DERMATOLOGY Online Nil

Competing Interests: None

\section{ONYCHOMADESIS SECONDARY ERYTHRODERMA EXFOLIATIVE DUE TO CIPROFLOXACIN}

\author{
Patricia Chang ${ }^{1}$, Monica Vanesa Vásquez Acajabón ${ }^{2}$ \\ ${ }^{1}$ Department of Dermatology, Hospital General de Enfermedades IGSS and Hospital \\ Ángeles, Guatemala \\ ${ }^{2}$ Hospital General de Enfermedades IGSS and Hospital Ángeles, Guatemala
}

Corresponding author: Patricia Chang, MD $\mathrm{PhD}$

pchang2622@gmail.com
Female patient 63 years old who was hospitalized due to erythroderma exfoliative (Fig. 1) after taking ciprofloxacin by urinary tract infection, 4 weeks later we began to observe the detachment of the finger and toenails from the proximal nail fold predominantly on the thumbs (Fig. 2), and the diagnosis of onychomadesis was done.

Nail diseases are common but no all people and doctors know about nail changes due to drug reaction or systemic diseases.

The present case shows the normal evolution of the nails after an injury due to drug reaction like erythroderma exfoliative.

The study of nail abnormalities is an important research area on actuality, due to they constitute around $5 \%$ to $10 \%$ of all dermatological diseases [1]. The onychomadesis is an ungual disease which consists in a separation of the nail plate from the matrix [1,2]. It can occur on fingernails or toenails [3]. At first, a cleavage appears under the proximal portion of the nail, followed by the disappearance of the juxtamatricial portion of the nail surface. In latent onychomadesis, the nail plate shows a transverse split (Beau lines) due to the transient complete inhibition of the nail growth, for at least 1-2 weeks [3,4]. Professionals describe onychomadesis like a severe form of Beu

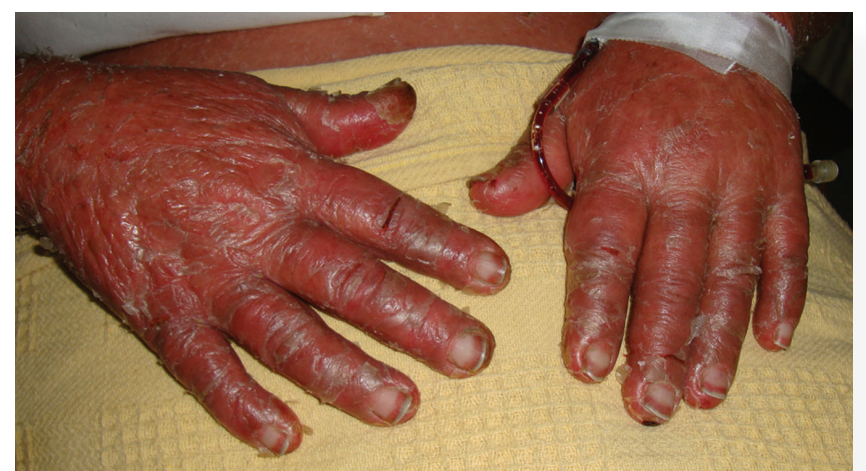

Figure 1. Fingernails at the beginning of the drug reaction. lines, and it may result in shedding of the nail [5].

This disease can be hereditary, acquired or traumatic (Fig. 3 a c) $[1,6]$. It usually results from serious generalized diseases (Fig. 4), bullous dermatoses (Fig.5), hand, foot and mouth disease, drug reactions (Fig. 6 a, b), severe psychological stress, or it may be idiopathic (Fig. 7 a, b) [4]. Onychomadesis also has been related with pyogenic granuloma and may be consequence of mid nerve injury, It was observed after cast immobilization [2]. Recently, onychomadesis has been associated with the use of valproic acid, azithromycin [4], penicillin, retinoids [7], and carbamazepin $[4,7]$. Some chemotherapy or X-ray treatments for cancer may also cause this condition $[3,4,7]$.

It is necessary to always take good care to avoid injury or breaking the nail plate and the cuticle. Therapy is intended to treat the underlying disease, this will allow normal nail plate regeneration with eventual growing of the affected areas $[3,6]$. It is contraindicated apply polish over the defect in the plate, as this will seal in any infective organisms that may be present, thus enhancing the possibility of further infection and injury to the matrix [3]. 


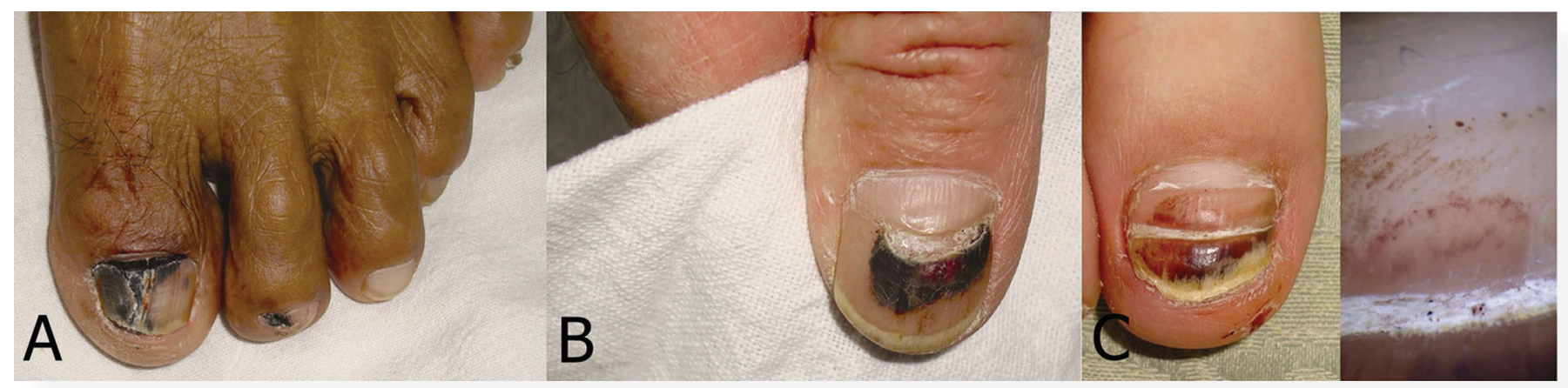

Figure 3 a,b,c. Onychomadesis due to major trauma.

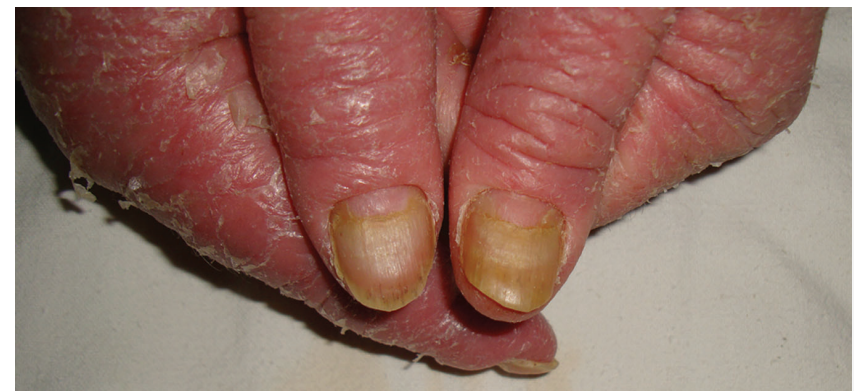

Figure 4. Onychomadesis due to psoriasic erythroderma.

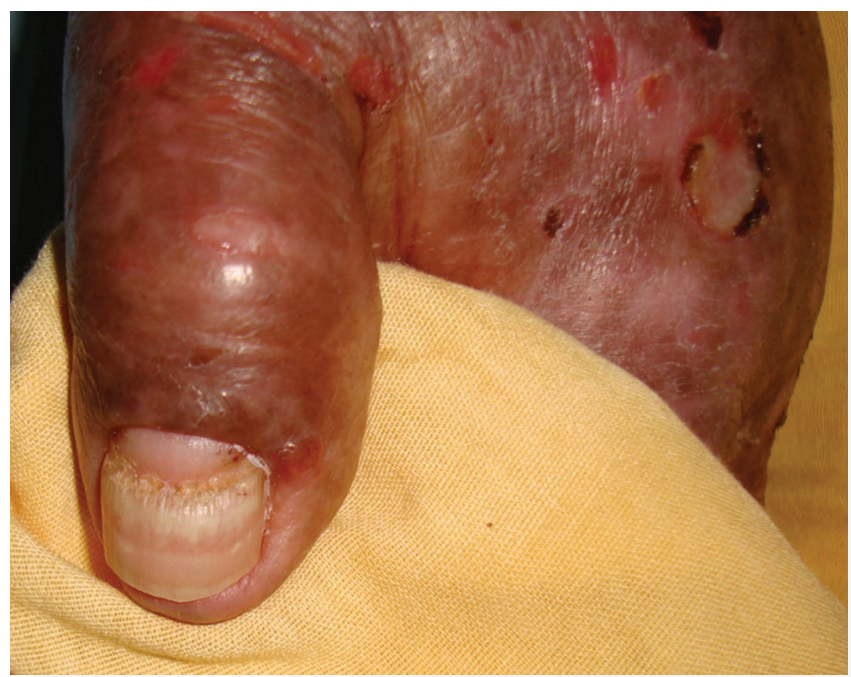

Figure 5. Bullous phemphigoid cause of onychomadesis.

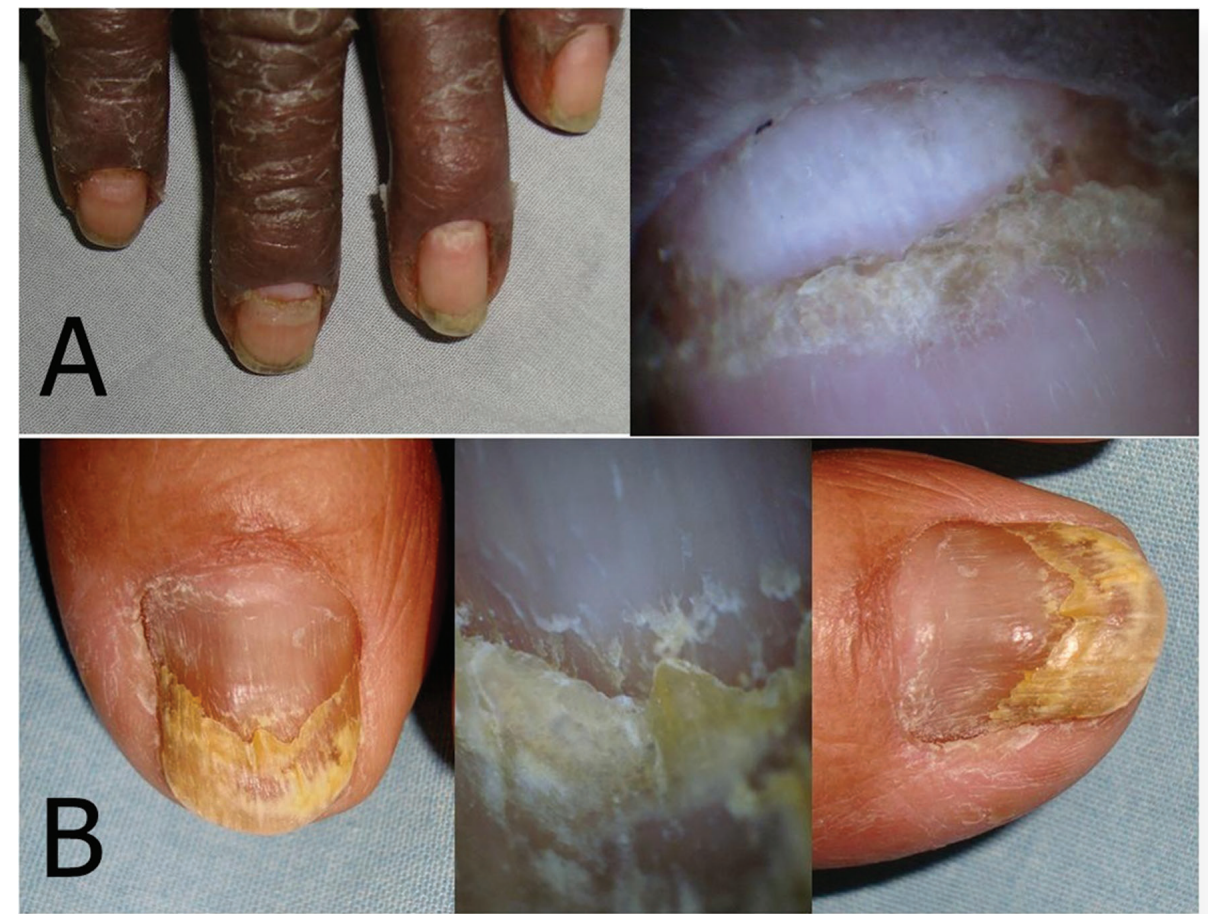

Figure 6 a,b. Onychomadesis due to drug reaction carbamazepin and cytostatics drug. 


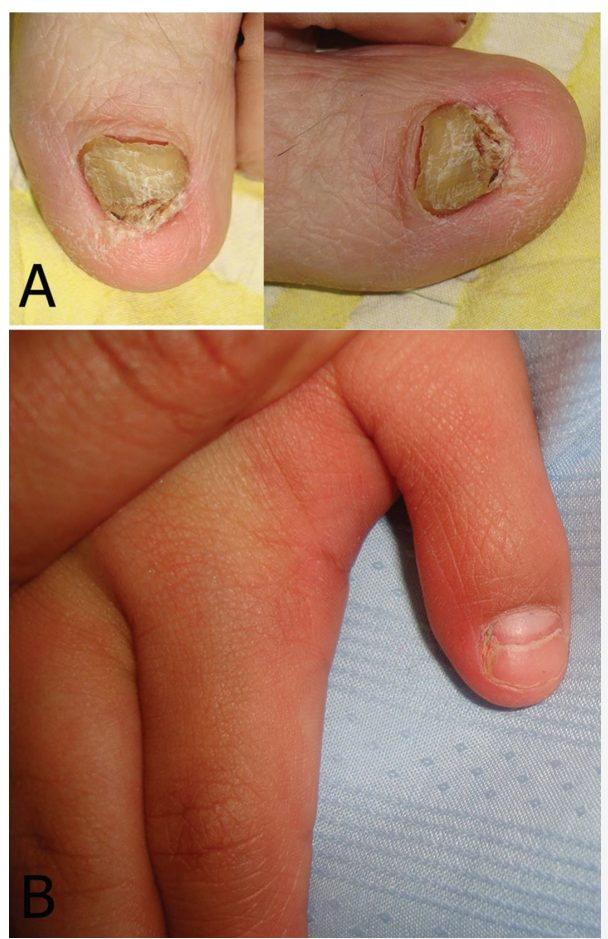

Figure 7. Idiopathic causes of onychomadesis.

\section{REFERENCES}

1. Arenas R. Dermatología Atlas, diagnóstico y tratamiento. Mexico DF. McGraw-Hill Interamericana, 1996:370.

2. Hardin JH. Idiopathic Sporadic Onychomadesis; Case Report and Literature Review. Arch Dermatol. 2012;148:769.

3. Mix G. The Nail and its disorders In Milady's Standard: nail technology, Schultes S. E., United States. Thomson Delmar Learning, 2012:125.
4. Rubin AI, Baran R. Physical Signs en: Diseases of the nails and their managment Baran R De Berker, D, Holzberg M, \& Thomas L. United Kingdom Willey-BlackWell, 2012:70-2.

5. Tosti A, Piraccini B, Lorizzo M, Daniel III R. Abnormal surface Color Atlas of Nails. New York Springer. 2010:34.

6. Singh G. Nail Changes and Disorders in Elderly. In: Nail \& Its Disorders, Sacchidanand S., A.S. Savita., New Delhi. Jaypee Brothers Medical Publishers, 2013;78.

7. Chang P, Escalante K. Onicomadesis; descripción de 12 pacientes, DCMQ. 2013;11:89-93.

\footnotetext{
Copyright by Patricia Chang, et al. This is an open access article distributed under the terms of the Creative Commons Attribution License, which
} permits unrestricted use, distribution, and reproduction in any medium, provided the original author and source are credited. 